\title{
Analisa Pengaruh Variasi Sudut Bevel Akibat Kombinasi Pengelasan Fcaw dan SMAW terhadap Kekuatan Impact Butt Joint pada Spesimen Pipa Api 5l Grade X42
}

\author{
Rizkiyah Ramadani ${ }^{1}$, Herman Pratikno ${ }^{1}$, dan Moch. Zaed Yuliadi ${ }^{2}$ \\ ${ }^{1}$ Jurusan Teknik Kelautan, Fakultas Teknologi Kelautan, Institut Teknologi Sepuluh Nopember (ITS) \\ ${ }^{2}$ PT PAL Indonesia, Jl. Ujung Surabaya PO Box 1134 \\ Jl. Arief Rahman Hakim, Surabaya 60111 Indonesia \\ e-mail: hermanp@oe.its.ac.id, mzaed@pal.co,id
}

\begin{abstract}
Abstrak - Kekuatan sambungan las pada suatu konstruksi perlu diperhatikan dengan baik dan pengujian pun perlu dilakukan untuk mengetahui ketahanan bahan terhadap suatu beban. Dalam penelitian tugas akhir ini bertujuan untuk mengetahui pengaruh sudut bevel dan kondisi optimal akibat kombinasi pengelasan FCAW dan SMAW terhadap kekuatan impact butt joint pada material pipa API $5 \mathrm{~L}$ grade X42. Variasi sudut bevel yang digunakan adalah 60o, 40o, dan 0o. Pengujian impact merupakan suatu upaya untuk mensimulasikan kondisi operasi material yang sering ditemui dalam perlengkapan transportasi atau konstruksi dimana beban tidak selamanya terjadi secara perlahan-lahan melainkan datang secara tiba-tiba, khususnya dalam konstruksi bangunan lepas pantai dimana beban secara tiba - tiba sangat memungkinkan untuk terjadi. Dari hasil penelitian yang dilakukan didapatkan bahwa nilai kekuatan impact pada sudut bevel 600 di bagian weld adalah sebesar $2.01 \mathrm{~J} / \mathrm{mm} 2$ dan bagian HAZ sebesar $2.08 \mathrm{~J} / \mathrm{mm} 2$. Sudut bevel 400 memiliki nilai pada bagian weld sebesar $2.10 \mathrm{~J} / \mathrm{mm} 2$ dan bagian HAZ sebesar $2.13 \mathrm{~J} / \mathrm{mm} 2$. Namun memiliki pengaruh yang jauh berbeda dengan sudut bevel 0o yaitu memiliki nilai impact sebesar $1.72 \mathrm{~J} / \mathrm{mm} 2$ untuk bagian weld dan $1.13 \mathrm{~J} / \mathrm{mm} 2$ untuk bagian HAZ . Kondisi optimal pengaruh sudut bevel terhadap kekutan impact adalah sudut 400 . Hal ini dikarenakan persentase ferrite metalografi struktur mikronya lebih banyak dibandingkan dengan sudut bevel 600 dan 00 dan juga memiliki nilai kekerasan yang rendah sehingga bersifat ulet menyebabkan nilai impact-nya lebih unggul. Selain itu efisensi dalam segi penghematan waktu kerja, perkerja maupun biaya produksi lebih baik.
\end{abstract}

Kata Kunci-Bevel, FCAW, Impact, SMAW.

\section{PENDAHULUAN}

$\mathrm{P}$ ENGEMBANGAN teknologi di bidang konstruksi yang semakin pesat dan tidak dapat dipisahkan dari pengelasan karena mempunyai peranan penting dalam rekayasa dan reparasi logam. Pembangunan konstruksi dengan logam pada masa sekarang ini banyak melibatkan unsur pengelasan khususnya bidang rancang bangun karena sambungan las merupakan salah satu pembuatan sambungan yang secara teknis memerlukan keterampilan yang tinggi bagi pengelasnya agar diperoleh sambungan dengan kualitas baik. Proses pengelasan biasanya digunakan untuk fabrikasi dalam aplikasi engineering, misalnya untuk pesawat terbang, otomotif, dan industri perkapalan [1], pipa saluran, dan lain sebagainya.

Pengelasan merupakan proses penyambungan antara dua bagian logam atau lebih dengan menggunakan energi panas. Menurut definisi dari Deutche Industrie Normen (DIN), pengelasan adalah penyambungan logam dengan ikatan metalurgi atau logam paduan yang dilaksanakan dalam keadaan lumer atau cair. Banyaknya penggunaan proses penyambungan dengan pengelasan dikarenakan pelaksanaan relatif lebih cepat, lebih ringan, biaya yang murah dan bentuk konstruksi lebih variatif [2]. Salah satu teknik pengelasan yang banyak dipakai untuk penyambungan pada konstruksi baja adalah las busur logam atau Flux cored Arc Welding (FCAW). FCAW adalah salah satu jenis las listrik yang memasok filler elektroda secara mekanis terus ke dalam busur listrik yang terbentuk di antara ujung filler elektroda dan metal induk. Gas pelindungnya menggunakan karbon dioxida $\mathrm{CO} 2$, atau campuran $\mathrm{CO} 2$ dengan argon. Sehingga pengelasan dapat dilakukan secara semi otomatis, maka dari itu memberi kenyamanan dalam pengoperasiannya dan memiliki keandalan yang tinggi [3]. Selain pengelasan FCAW, jenis pengelasan lain yang sering digunakan adalah SMAW (Shielded Metal Arc Welding). Dalam pengelasan ini, logam induk mengalami pencairan akibat pemanasan dari busur listrik yang timbul anta vcdra ujung elektroda berbungkus fluks dan permukaan benda kerja. Kombinasi pengelasan seperti ini banyak dilakukan agar hasil pengelasan pada material bahan dapat maksimal.

Proses pengelasan, pada dasarnya memiliki tujuh macam sambungan, yaitu: butt joint, backing joint, $\mathrm{T}$ joint, Cross joint, overlap joint, corner joint, dan edge joint [4]. Sambungan - sambungan tersebut memiliki karakteristik sendiri-sendiri tergantung kondisi material yang dikerjakan. Maka untuk kualitas las yang baik harus dipilih jenis sambungan yang sesuai sudut tertentu agar nantinya mampu menerima beban statis, beban dinamis, atau keduanya.

Uji impact adalah pengujian DT (Destructive Test) dengan menggunakan pembebanan yang cepat (rapid loading). Pengujian impact merupakan suatu pengujian yang mengukur ketahanan bahan terhadap beban kejut. Inilah yang 
membedakan pengujian impact dengan pengujian tarik dan kekerasan, dimana pembebanan dilakukan secara perlahanlahan.

\section{METODOLOGI PENELITIAN}

Metode penelitian yang digunakan dalam penelitian ini adalah penelitian eksperimental nyata. Material yang digunakan adalah pipa API 5L Grade X42 sebanyak 6 buah dengan Outer Diameter (OD) $165 \mathrm{~mm}$ atau 6.5 inch dan wall thickness $11 \mathrm{~mm}$.

\section{A. Proses Pengelasan}

Pengelasan yang dilakukan adalah kombinasi pengelasan SMAW untuk layer root lalu pengelasan FCAW untuk layer fill dan cap. Elektroda yang digunakan untuk pengelasan SMAW adalah E7016 dengan diameter $2.6 \mathrm{~mm}$ dan E701-T dengan diameter $1.2 \mathrm{~mm}$ untuk elektoda pengelasan FCAW. Varibel bebas yang digunakan pada penelitan ini adalah sudut bevel $0 \mathrm{o}, 40 \mathrm{o}$, dan 60o. Posisi pengelasan yang dilakukan yaitu 5G. Prosedur pengerjaan pengelasan mengacu pada WPS berdasarkan standard API 1104 tentang prosedur pengelasan pada pipa.

Arus dan tegangan pada pengelasan sudut bevel $0^{\circ}$ dapat dilihat pada tabel pengelasan bevel 0 .

Arus dan tegangan pada pengelasan sudut bevel $40^{\circ}$ dan $60^{\circ}$ dapat dilihat pada tabel pengelasan bevel 40 .

\section{B. Pembuatan spesimen Uji Impact}

Pada penelitian ini pembuatan uji spesimen dapat dilihat pada Gambar 2.1 - 2.3.

\section{ANALISA DATA DAN PEMBAHASAN}

\section{A. Foto Struktur Mikro}

Dari hasil pengujian mikro didapatkan bahwa butir-butir ferit cenderung lebih halus sedangkan butir perlit lebih kasar. Butir perlit cenderung keras dan getas sedangkan butir ferit cenderung lunak atau ulet. Kegetasan sendiri disebabkan oleh butir-butir yang kasar. Apabila persentase struktur mikro ferit lebih banyak dibandingkan perlite, maka dapat menahan rambatan retak yang terjadi. Semakin banyak persentase ferit maka material memiliki nilai ketangguhan yang semakin tinggi. Berikut adalah foto struktur mikro pada daerah weld metal perbesaran $400 \mathrm{X}$ dapat dilihat pada Gambar 3.1.

Berikut adalah foto struktur mikro pada daerah HAZ perbesaran 400x dapat dilihat pada Gambar 3.2. Berikut adalah tabel persentase fasa dari perhitungan metode point counting pada struktur mikro dapat dilihat pada Tabel 3.1.

Dari tabel 3.1 didapatkan hasil sudut bevel $60 \mathrm{o}$ memiliki fasa ferrite sebesar $33.11 \%$, perlite sebesar $54.67 \%$ dan martensit sebesar $12.22 \%$. Pada sudut bevel 40o didapatkan fasa ferrite sebesar $42.11 \%$, perlite sebesar $57.44 \%$. Pada sudut bevel 0o didapatkan fasa ferrite sebesar $40.89 \%$ dan perlite sebesar $59.11 \%$.

Dari tabel 3.2 didapatkan hasil sudut bevel 60o memiliki fasa ferrite sebesar $26.44 \%$, perlite sebesar $55.4 \%$. Pada sudut bevel 40o didapatkan fasa ferrite sebesar $44.11 \%$, perlite sebesar $55.4 \%$. Pada sudut bevel 0o didapatkan fasa ferrite sebesar $22.56 \%$ dan perlite sebesar $77.4 \%$.

Dari pengolahan data struktur mikro dengan metode point counting didapatkan bahwa di bagian weld metal sudut bevel 60o memiliki fasa ferrite terendah yaitu $33.11 \%$ dan juga terbentuk fasa martensit yaitu terjadinya pendingan cepat sehingga material bersifat getas hal ini dikarenakan sudut bevel 60o memiliki luas penampang pada bagian las lebih besar dibandingkan dengan sudut bevel 40o dan 0o sehingga cooling rate terjadi lebih cepat menyebabkan pendinganan pun terjadi lebih cepat. Pada sudut bevel 0o di bagian HAZ memiliki fasa ferrite terendah yaitu 22.56\%. Besarnya luasan HAZ dipengaruhi oleh masukan panas yang dikenakan pada material. Semakin besar masukan panas, maka semakin besar pula luasan HAZ yang terbentuk [6] Hal ini dapat menurunkan sifat mekanik dari material. Penurunan sifat mekanik ini akibat dari laju pendinginan pada daerah HAZ yang relatif lebih cepat sehingga menyebabkan berubahnya struktur kristal HAZ menjadi lebih besar. Struktur mikro ferit lebih rapat (halus), sehingga menahan rambatan retak yang terjadi. Semakin halus ferit maka mempunyai ketangguhan yang semakin tinggi [7]

\section{B. Pengujian Impact}

Pada gambar 4.5 menunjukan hasil patahan specimen setelah proses uji impact. Spesimen A adalah sudut bevel 60o, specimen B adalah sudut bevel 40o dan specimen C adalah sudut bevel 0o. Pada baris 1 menunjukan specimen bagian weld metal dan pada baris 2 menunjukan specimen bagian HAZ. Patahan yang dialami oleh specimen A dan specimen B hampir sama namun jauh berbeda dengan patahan pada specimen $\mathrm{C}$, terlihat pada bagian weld dari spesimen $\mathrm{C}$ mengalami patah sempurna yang berarti bahwa specimen tersebut sangat getas. Permukaan patah membantu untuk menentukan kekuatan impact dalam hubungannya dengan temperatur transisi bahan. Daerah transisi yaitu daerah dimana terjadi perubahan patahan ulet ke patahan getas [8]. Bentuk perpatahan dapat dilihat langsung dengan mata telanjang atau dapat pula dengan bantuan mikroskop.

Dari hasil pengujian impact yang telah dillakukan lalu dilakukan perhitungan rata - rata maka didapatkasan hasil berupa diagram perbandingan pada gambar 3.4

Pengujian Impact dilakukan di bagian weld dan HAZ pada setiap spesimen. Dari diagram perbandingan sudut bevel terhadap nilai impact pada material A sudut bevel 60o menunjukan nilai rata - rata pada HAZ sebesar $2.08 \mathrm{~J} / \mathrm{mm} 2$ dan nilai rata - rata pada weld sebesar $2.01 \mathrm{~J} / \mathrm{mm} 2$. Pada material B sudut bevel $40 \mathrm{o}$ menunjukan nilai rata - rata pada HAZ sebesar $2.13 \mathrm{~J} / \mathrm{mm} 2$ dan weld sebesar $2.10 \mathrm{~J} / \mathrm{mm} 2$ sedangkan pada material $\mathrm{C}$ sudut bevel 0o menunjukan nilai rata - rata pada HAZ sebesar $1.13 \mathrm{~J} / \mathrm{mm} 2$ dan pada weld sebesar $1.72 \mathrm{~J} / \mathrm{mm} 2$.

Dari diagram pada gambar 3.4 dapat dianalisa bahwa nilai ketangguhan di bagian weld metal maupun HAZ pada sudut bevel 40o lebih unggul daripada sudut bevel 60o dan sudut 
Tabel Arus dan tegangan pada pengelasan sudut bevel $0^{\circ}$

\begin{tabular}{lll}
\hline \hline Weld Pass & Amps (A) & Volts (V) \\
\hline Root & $50-80$ & $19-20$ \\
Fill & $100-130$ & $20-27$ \\
Cap & $100-150$ & $20-30$ \\
\hline \hline
\end{tabular}

Tabel Arus dan tegangan pada pengelasan sudut bevel $40^{\circ}-60^{\circ}$

\begin{tabular}{lll}
\hline \hline Weld Pass & Amps (A) & Volts (V) \\
\hline Root & $50-80$ & $17-20$ \\
Fill & $80-120$ & $20-25$ \\
Cap & $80-120$ & $20-27$ \\
\hline \hline
\end{tabular}

Tabel 3.1 Hasil pengujian mikro pada daerah weld metal

\begin{tabular}{cccc}
\hline \hline Sudut Bevel & Ferrite (\%) & Perlite (\%) & Martensit (\%) \\
\hline $60^{\circ}$ & 33.11 & 54.67 & 12.22 \\
$40^{\circ}$ & 42.11 & 57.44 & 0 \\
$0^{\circ}$ & 40.89 & 59.11 & 0 \\
\hline \hline
\end{tabular}

Tabel 3.2 Hasil pengujian mikro pada daerah HAZ

\begin{tabular}{ccc}
\hline \hline Sudut Bevel & Ferrite (\%) & Perlite (\%) \\
\hline $60^{\circ}$ & 26.44 & 73.6 \\
$40^{\circ}$ & 44.56 & 55.4 \\
$0^{\circ}$ & 22.56 & 77.4 \\
\hline \hline
\end{tabular}

Tabel 3.3 Hasil Uji Kekerasan pada weld metal

\begin{tabular}{cccccc}
\hline \hline \multirow{2}{*}{ Garis } & \multirow{2}{*}{ Titik } & Daerah & \multicolumn{3}{c}{ Sudut Bevel } \\
& & & $60^{\circ}$ & $40^{\circ}$ & $0^{\circ}$ \\
\hline Top & 1 & Weld & 132.9 & 114.8 & 152.4 \\
Middle & 2 & Metal & 161.1 & 152.30 & 177 \\
Bottom & 3 & & 162 & 177 & 150.9 \\
& Rata-rata & & $\mathbf{1 5 2 . 0 0}$ & $\mathbf{1 4 8 . 0 3}$ & $\mathbf{1 6 0 . 1 0}$ \\
\hline \hline
\end{tabular}

bevel 40o. Hal ini di karenakan sudut bevel 40o memiliki penetrasi las yang cukup baik. Selain itu berdasarkan hasil analisa metalografi struktur mikro menunjukan bahwa nilai persentase ferit di bagian weld metal maupun HAZ pada sudut bevel 40o lebih tinggi daripada sudut bevel 60o dan sudut bevel 0o sehingga cenderung bersifat lebih ulet. Keunggulan lain dari sudut bevel 40o yaitu pada saat pengelasan memerlukan relatif lebih sedikit kawat las sehingga penyelesaiannya lebih cepat, lebih menghemat waktu, menghemat biaya produksi dan pada akhirnya lebih efisien. Sedangkan pada sudut bevel 00 menunjukan nilai ketangguhan paling rendah hal ini dikarenakan sudut bevel 0o
Tabel 3.4 Hasil Uji Kekerasan pada HAZ dalam satuan

\begin{tabular}{|c|c|c|c|c|c|}
\hline \multirow{2}{*}{ Garis } & \multirow{2}{*}{ Titik } & \multirow{2}{*}{ Daerah } & \multicolumn{3}{|c|}{ Sudut Bevel } \\
\hline & & & $60^{\circ}$ & $40^{\circ}$ & $0^{\circ}$ \\
\hline & 1 & & 119.2 & 103.3 & 129.2 \\
\hline & 2 & & 128.7 & 103.7 & 134.1 \\
\hline & 3 & & 106.2 & 92.7 & 114.5 \\
\hline \multirow[t]{3}{*}{ Top } & 4 & $\mathrm{HAZ}$ & 111.8 & 79.5 & 103.2 \\
\hline & Rata-ra & & 116.475 & 94.8 & 120.25 \\
\hline & 1 & & 157 & 115.4 & 124.4 \\
\hline \multirow[t]{5}{*}{ Middle } & 2 & HAZ & 129.6 & 124.6 & 175.1 \\
\hline & Rata-ra & & 143.30 & 120 & 149.75 \\
\hline & 1 & & 162.4 & 124.1 & 139 \\
\hline & 2 & & 156.3 & 125.5 & 154.5 \\
\hline & 3 & & 140 & 185.3 & 144.2 \\
\hline \multirow[t]{2}{*}{ Bottom } & 4 & $\mathrm{HAZ}$ & 127.1 & 119.9 & 137.4 \\
\hline & Rata-ra & & 146.45 & 138.70 & 143.78 \\
\hline \multicolumn{3}{|c|}{ Rata-rata total HAZ } & 135.41 & 117.83 & 13793 \\
\hline
\end{tabular}

memiliki gap yg cukup besar yaitu $6 \mathrm{~mm}$ sehingga penetrasi las tidak penuh dan cukup sulit sehingga menyebabkan banyak cacat. Selain itu berdasarkan hasil metalografi struktur mikro baik weld metal maupun HAZ sudut bevel 0o memiliki nilai perlite lebih tinggi daripada nilai ferrite sehingga cenderung lebih getas. Hasil pengujian impact pada penelitian ini menunjukkan bahwa terjadi penurunan nilai impact untuk masing-masing variasi sudut bevel dengan tingkat prosentase yang berbeda-beda. Penurunan nilai impact ini disebabkan oleh peningkatan nilai persentase fase perlit pada masingmasing variasi sudut bevel. Fase perlit menyebabkan naiknya nilai kekerasan. Semakin tinggi nilai kekerasan suatu material menggambarkan bahwa material tersebut semakin kuat, tetapi nilai ketangguhanya akan menurun. Nilai ketangguhan (fracture toughness) merupakan gambaran seberapa besar ketahanan suatu material untuk menahan perambatan retak [9] Semakin besar nilai fracture toughness-nya berarti semakin baik material tersebut, karena ketahanan terhadap laju retak juga semakin tinggi.

\section{Uji Kekerasan (Vickers)}

Dari data-data yang terdapat pada tabel 3.3 maka dapat diplot kedalam diagram pada gambar 3.5.

Dari diagram pada gambar 3.5 menunjukan nilai kekerasan pada weld metal dengan nilai terendah yaitu sudut bevel 40o sebesar $148.03 \mathrm{~kg} / \mathrm{mm} 2$ lalu pada sudut 60o sebesar 152 $\mathrm{kg} / \mathrm{mm} 2$ dan nilai tertinggi pada sudut bevel 0o sebesar 160.1 $\mathrm{kg} / \mathrm{mm} 2$. Hal ini menunjukan bahwa sudut bevel 0o bersifat paling getas sedangkan sudut $40 \mathrm{o}$ bersifat paling ulet. Selanjutnya nilai kekerasan bagian HAZ pada tabel 3.4

Dari data-data yang terdapat pada tabel 3.4 maka dapat diplot kedalam diagram pada gambar 3.6. Dari diagram pada gambar 3.6 menunjukan nilai kekerasan pada HAZ dengan nilai terendah yaitu sudut bevel 40o sebesar $117.83 \mathrm{~kg} / \mathrm{mm} 2$ lalu pada sudut bevel 60o sebesar $135.41 \mathrm{~kg} / \mathrm{mm} 2$ dan nilai 

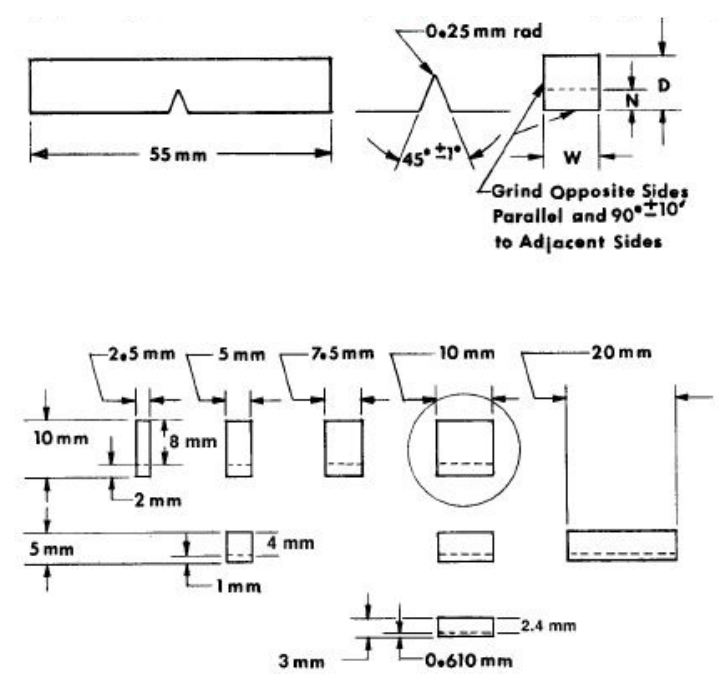

Gambar 2.1 Dimensi spesimen uji impact ASTM E23 [5]

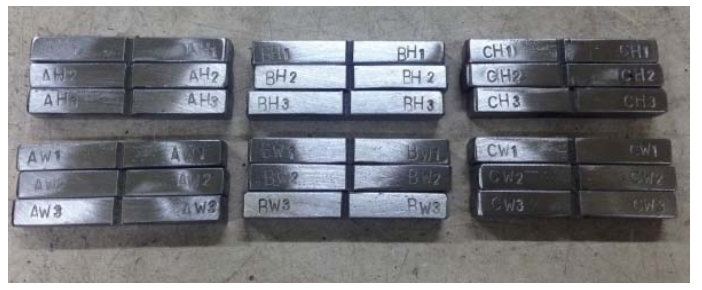

Gambar 2.2 Spesimen uji imapct

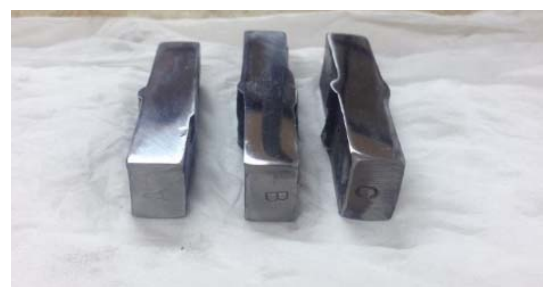

Gambar 2.3 Spesimen yang sudah di poles untuk foto Struktur Mikro dan Uji Kekerasan

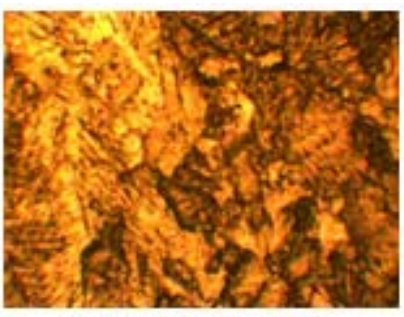

A (sudut bevel $60^{\circ}$ )

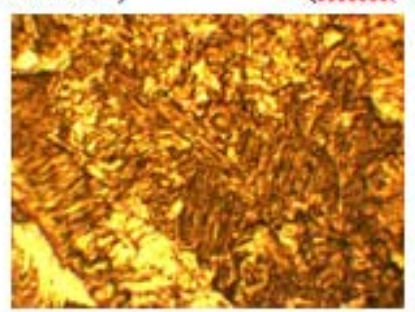

$\mathrm{C}$ (sudut bevel $0^{\circ}$ )

Gambar 3.1 Struktur mikro bagian weld metal

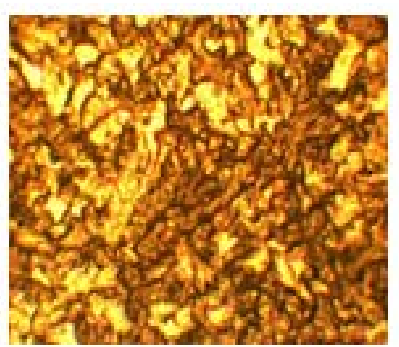

A (sudut bevel $60^{\circ}$ )

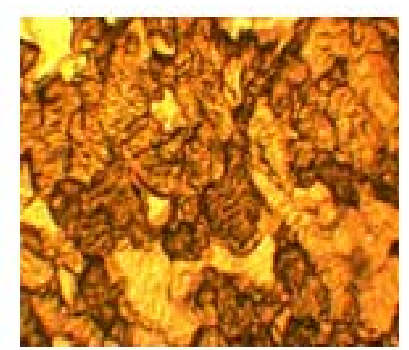

B (sudut bevel $40^{\circ}$ )

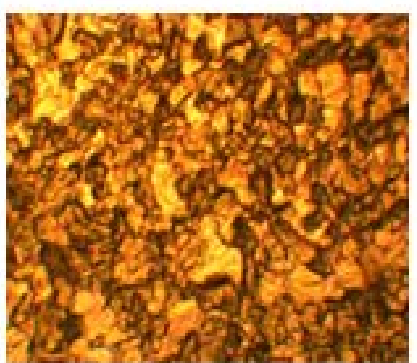

$\mathrm{C}$ (sudut bevel $0^{\circ}$ )

Gambar 3.2 Struktur mikro bagian HAZ

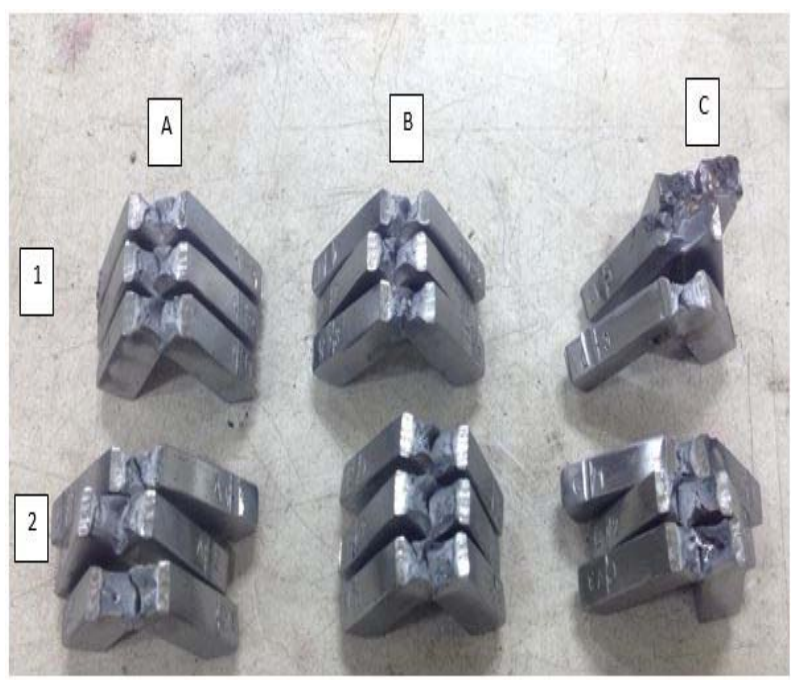

Gambar 3.3 Hasil Patahan Spesimen Akibat Uji Impact

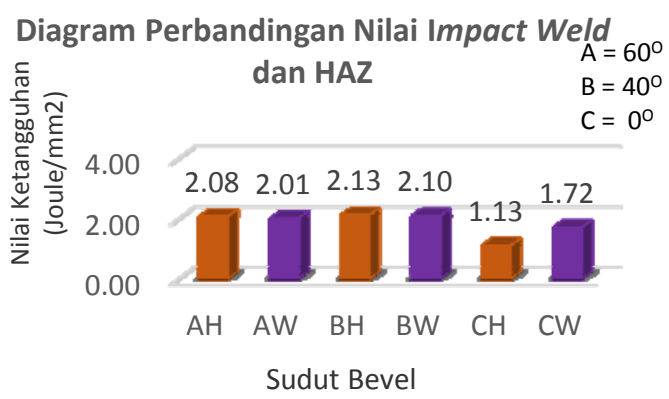

Gambar 3.4 Diagram perbandingan nilai impact weld dan HAZ 


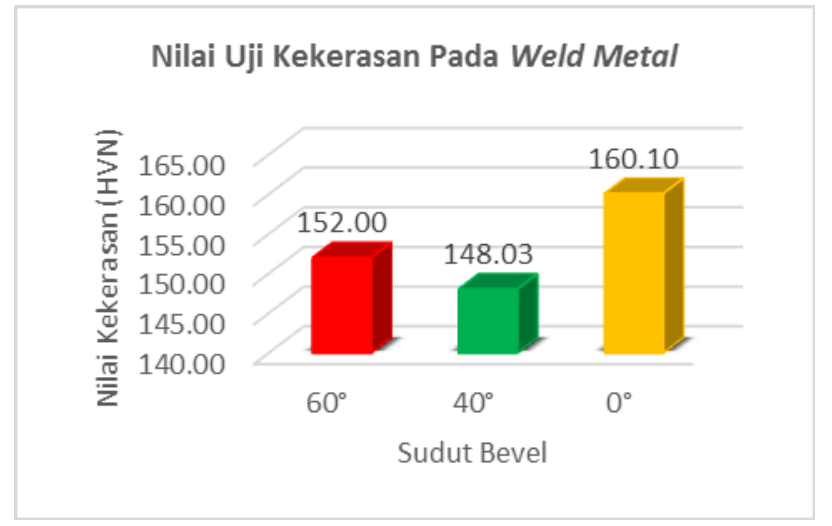

Gambar 3.5 Diagram pengaruh sudut bevel pada weld metal terhadap nilai kekerasan

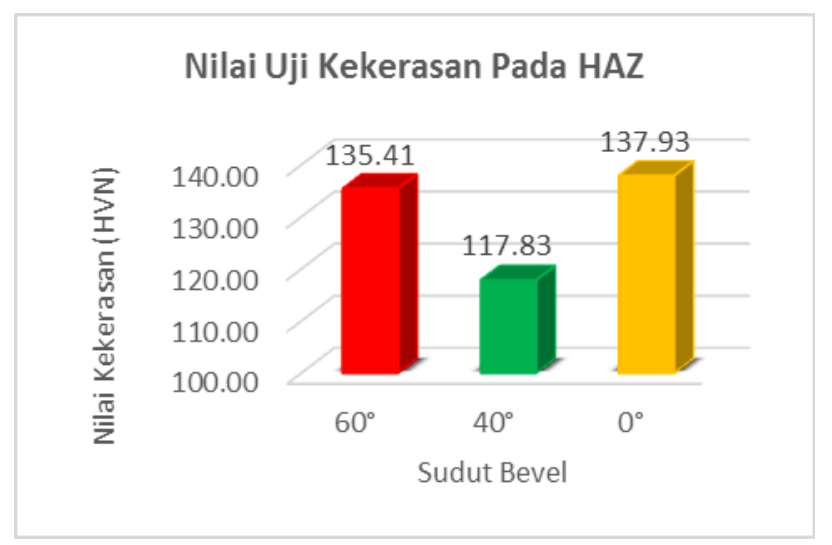

Gambar 3.6 Diagram pengaruh sudut bevel pada HAZ terhadap nilai kekerasan

tertinggi pada sudut bevel 0o sebesar $137.93 \mathrm{~kg} / \mathrm{mm} 2$. Hal ini menunjukan bahwa sudut bevel 0o bersifat paling getas sedangkan sudut $40 \mathrm{o}$ bersifat paling ulet. Dari hasil keseluruhan pengujian kekerasan di bagian weld maupun HAZ menunjukan nilai kekerasan tertinggi pada sudut bevel 0o yaitu 160.1 HV untuk bagian weld dan $137.93 \mathrm{HV}$ pada bagian HAZ. Hal ini membuktikan bahwa sudut 0o memiliki sifat paling getas diantara sudut 40o dan 0o dikarenakan memiliki nilai kekerasan paling tinggi namun memiliki nilai ketangguhan paling rendah. Hal lain ditunjukan pada sudut bevel 40o karena memiliki nilai kekerasan terendah yaitu 148.03 HV di bagian weld dan 117.83 HV di bagian HAZ namun memiliki nilai ketangguhan yg tinggi yang mengartikan bahwa sudut ini bersifat paling ulet dibandingkan sudut 60 o dan 0 o.

\section{KESIMPULAN}

\section{A. Kesimpulan}

1. Nilai kekuatan impact pada sudut bevel 60o di bagian weld adalah sebesar $2.01 \mathrm{~J} / \mathrm{mm} 2$ dan bagian HAZ sebesar $2.08 \mathrm{~J} / \mathrm{mm} 2$. Sudut bevel $40 \mathrm{o}$ memiliki nilai pada bagian weld sebesar $2.10 \mathrm{~J} / \mathrm{mm} 2$ dan bagian HAZ sebesar $2.13 \mathrm{~J} / \mathrm{mm} 2$. Namun memiliki pengaruh yang jauh berbeda dengan sudut bevel 0o yaitu memiliki nilai impact sebesar $1.72 \mathrm{~J} / \mathrm{mm} 2$ untuk bagian weld dan 1.13 $\mathrm{J} / \mathrm{mm} 2$ untuk bagian HAZ.

2. Kondisi optimal pengaruh sudut bevel pada kombinasi pengelasan SMAW dan FCAW butt joint terhadap kekuatan impact pada spesimen pipa API 5L Grade X42 adalah sudut $40 \mathrm{o}$. Hal ini dikarenakan persentase ferrite metalografi struktur mikronya lebih banyak dibandingkan dengan sudut bevel 60o dan 0o dan juga memiliki nilai kekerasan yang rendah sehingga bersifat ulet menyebabkan nilai impact-nya lebih unggul. Selain itu berdasarkan penelitian sebelumnya bahwa sudut bevel 40o memiliki efisensi dalam segi penghematan waktu kerja, perkerja maupun biaya produksi lebih baik [10].

\section{DAFTAR PUSTAKA}

[1] Gery , D., Long, H., Maropoulos, P. 2005. "Effects of welding speed, energy input and heat source distribution on temperature variations in butt joint welding”. Journal of Materials Processing Technology. 167 : 393-401

[2] Cary, H.B., 1994, Modern Welding Technology. Prentice Hall : Englewood

[3] Song, J., Peters. J., Noor, A., and Michaleris, P., 2003., “ Sensitivity Analysis of The Thermomechanical Response of Welding Joints" Journal of Solids and Struktures 40, Hal 4167-4180.

[4] ASME section IX. 2001. "Qualification Standard For Welding And Brazing Procedures, Welders, Brazers, And Welding And Brazing Operators”. New York : The American Society of Mechanical Engineers New York.

[5] ASTM .(2008). ASTM E23-07 Standard Test Methods for Notched Bar Impact Testing of Metallic Materials. United Kingdom : SAI Global ILI Publishing

[6] Zakharov, B. 1962. Heat Treatment of Metal. Moscow: Peace Publisher.

[7] Stanhope, and Lancaster. (1996). Community Heaalt Nursing : Procces and Practice for Promoting Health. St. Louis : Mosby Company

[8] Okumura T, Wiryosumarto H. 1994 "Teknologi Pengelasan Logam”. Jakarta : Pradnya Paramita.

[9] Riyadi,F, dan Setyawan,D.,2011.,”'Analisa Mechanical dan Metallugrical Pengelasan Baja Karbon A36 dengan Metode SMAW". Surabaya : Institut Teknologi Sepuluh Nopember

[10] Yuliadi , Zaed. 2012. "Strategi Percepetan dan Efisiensi pengelasan dengan Desain Sudut Bevel 400 di PT PAL INDONESIA (PERSERO)”. Surabaya : PT PAL INDONESIA (PERSERO 